\title{
Effect of vortex formation on sediment transport at dual pipe intakes
}

\author{
M R KHANARMUEI, H RAHIMZADEH*, A R KAKUEI and H SARKARDEH \\ Department of Mechanical Engineering, Amirkabir University of Technology, Hafez Avenue, Tehran, Iran \\ e-mail: rahimzad@aut.ac.ir
}

MS received 25 April 2015; revised 17 January 2016; accepted 20 February 2016

\begin{abstract}
Vortex formation and subsequent sediment transport into the intake due to sea water withdrawal is one of the problems in coastal engineering. The effect of vortex formation on rate of sediment transport at coastal dual pipe intakes was investigated using a scaled physical model. Experiments were performed on dual pipe intakes at three common intake withdrawal directions (vertical, horizontal and with angle of $45^{\circ}$ ). In each experiment, the class of vortex with respect to its strength was determined. Particle tracking velocimetry (PTV) was employed to measure tangential velocity of vortices. Results indicated that the rate of sediment transport was considerably affected by the strength of formed vortices. The rate of transported sediment was increased by increasing the strength of formed vortex. Moreover, amount of sediment transport was affected by angle of pipe intakes. It could be concluded that the minimum and maximum rates of sediment transport occur for inclined and horizontal intakes, respectively.
\end{abstract}

Keywords. Sediment; vortex; dual intakes; intake direction; physical model.

\section{Introduction}

The most important aims in design of sea water withdrawal intakes are to reach the maximum discharge and minimum rate of sediment transport into the intake pipes. The type of transported sediments through the sea water intakes are different and divided into the coarse sediments as bed load and fine sediments as suspended load [1]. Some of the coarse sediments tend to deposit within the intake and gradually cause blockage and increase roughness in the boundaries. In case of direct pumping station from the intake, the dispersion part of coarse sediments may march through the suction of the pump, this cause some damages to the impeller. The passed fine suspended sediments through the intake and pump will transfer through the downstream parts of hydraulic system and consequent some damages into the pipeline. Formation of vortices at an intake can cause operational problems such as increasing energy loss, decreasing discharge coefficient, pulling floating particles and increasing noise and vibration. The vertical distance between an intake and water surface, $S$, is called the submerged depth (figure 1). The value of the submerged depth at which entrain air and trash into the intake is, $S_{c}$, called the critical submerged depth [2].

Different classifications are available for vortices. In general, intake vortices divide into surface and subsurface vortices where form from the free surface of the water and the bed respectively [4]. Sarkardeh et al [5] categorized

*For correspondence vortices regarding their strength into the three classes. Vortices of Class $\mathrm{C}$ are considered to be safe and weak rotations of flow or slight surface drop may be observed in this class. The Class B surface vortices are stronger and the rotation in water surface extends down to the intake. This extension may drag debris and trash into the intake. The strongest vortices, which should be avoided, are categorized in Class A. In this class air bubbles are trapped and conveyed down from the water surface to the intake. In the strongest state, a stable air core is formed in the center of the vortex which allows air to steadily enter the intake. Carriveau et al [6] also introduced two categories of free surface intake vortices. In the first case, when the constantly supplied vorticity in the reservoir is reduced (while maintaining the withdrawal rate) the vortex would disintegrate. This vortex is labeled as non-purely stretching-sustained (NPSS). In the second case, when the strain field is strong enough, without an external source of vorticity, minor asymmetries in the near radial intake flow are concentrated and amplified into a vortex core that is purely stretching sustained (PSS).

Three basic beach types are dissipative, intermediate and reflective [7] (figure 2).

Vortices and their consequents were clearly introduced in the literature and many attempts were performed to discover this phenomenon. Several analytical, numerical and experimental studies on the free surface vortex formation are available for the single intake such as [5, 8-17]. There are only few studies dealing with dual pipe intakes. Denny and Young [18] experimentally investigated the critical 


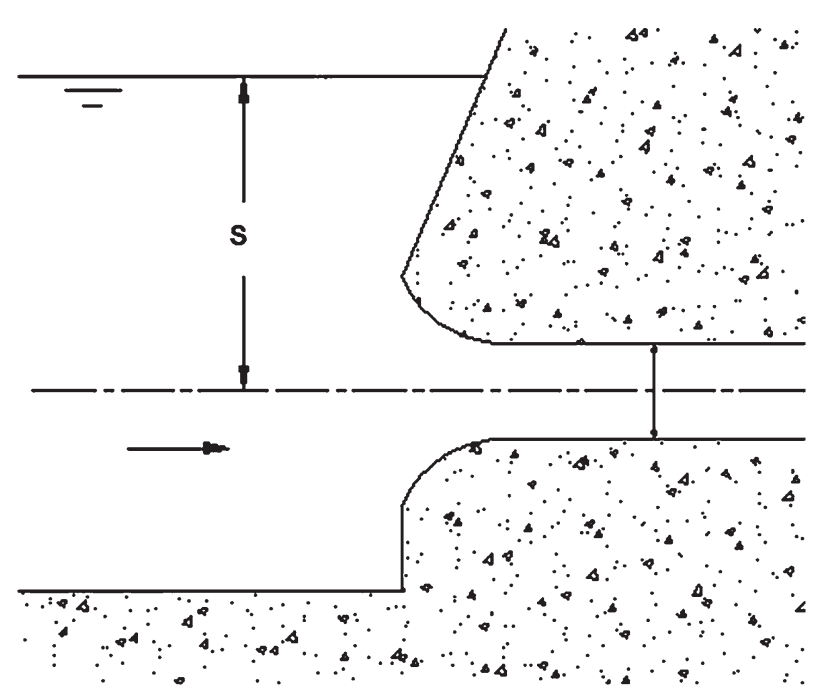

Figure 1. Submerged depth at intakes [3].

(a) Dissipative beach

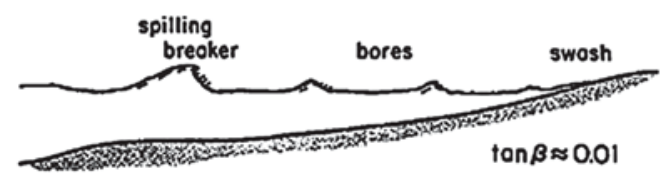

(b) Intermediate beach

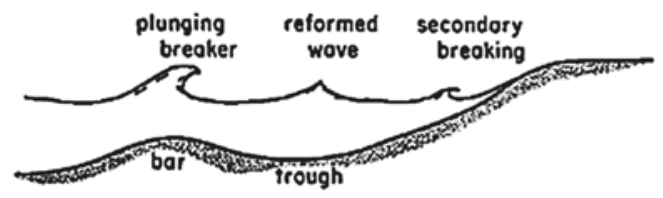

(c) Reflective beach

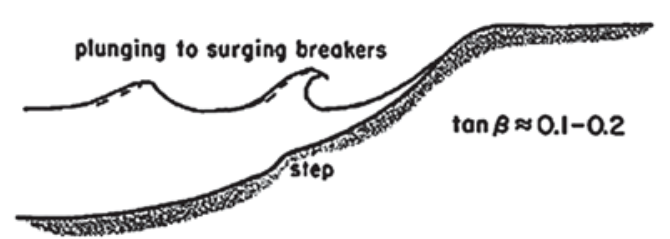

Figure 2. Schematic view of different beach types [7].

submerged depth for single, double, and triple intakes into a pump-sump. Jansen [19] used three-dimensional (3D) numerical simulations of the inviscid flow in single- and two-pump intakes and compared the results with laboratory experiments. Yildirim et al [20] analytically and experimentally investigated effects of dimensions and relative positions of dual pipe intakes on the critical submerged depth. Yildirim et al [21] analytically and experimentally studied the critical submerged depth for dual rectangular intakes. Several analytical and experimental studies on the sediment transport are also available for the single intake which most of them have been focused on reduction of sediment transport. Kerssens and Van Urk [22] conducted experiments relating to the sediment transport and bed-level changes for a water intake and compared experimental results with a one-dimensional mathematical model. Johnson [23] considered the design factors of power intakes and showed that the control of sediment transport is an important parameter in design of intakes. Michell et al [24] studied the erosion-promoting vanes and a skimming wall effects on control of sediment problem at water intakes. Moghadam et al [25] investigated sediment delivery to a 30 degree water intake from trapezoidal canal, experimentally. They found that the flow pattern at upstream of the intake has a considerable effect on amount of suspended sediment which enters into the intake.

Previous studies indicate that the sediment transport, considerably related to the strength of formed vortices at intakes. Therefore, reduction in strength of vortices causes reduction in the concentration of sucked sediment into the intakes [26]. Selecting the proper intake direction and geometric shape of the intake entrance can modify the flow pattern in such a way to reduce the sediment entry. Most studies in field of sediment transport dealt with one intake, but in the present study, the experiments were performed on dual pipe intakes with three different directions.

\section{Experimental setup}

Experiments were conducted on dual pipe intakes passing through a reservoir with $200 \mathrm{~cm}$ long, $200 \mathrm{~cm}$ wide, and 120 $\mathrm{cm}$ deep and a sediment retention reservoir (figure 3). The scale of the constructed experimental setup was $1: 10$. This scale was selected based on hydraulic similarity between model and prototype coastal intakes. With respect to physic of sediment transport and free surface flow at intakes, the governing forces are gravity and inertia, because of this reason the Froude number $(F r=V / \sqrt{g D})$ was selected as dimensionless variable. To avoid the scale effects in the physical model studies and eliminating the effect of Reynolds $(\operatorname{Re}=\rho V D / \mu)$ and Weber $\left(W e=\rho v^{2} D / \sigma\right)$ numbers, various criteria were suggested. According to [14] $W e>120$, [9] $\operatorname{Re}>1.1 \times 10^{5}$, [15] $\operatorname{Re}>1.4 \times 10^{5}$, $W e>720$ and [27] $\operatorname{Re}>7.7 \times 10^{4}$, We $>600$, viscosity and surface tension effects are insignificant. Minimum $R e$ and $W e$ values in present work were more than the minimum values suggested by other researchers.

Intakes and reservoir side walls were made of Perspex for visual observation. The diameter of the intakes $(D)$ was equal to $15 \mathrm{~cm}$. The discharge valves were mounted on outflow pipes. Usually the water enters the reservoir with high velocity that causes disturbance in the flow. To overcome this problem at the entrance of the reservoir a 


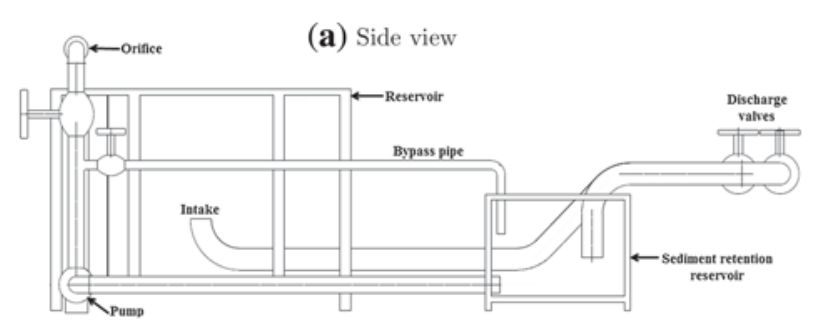

(b) Plan

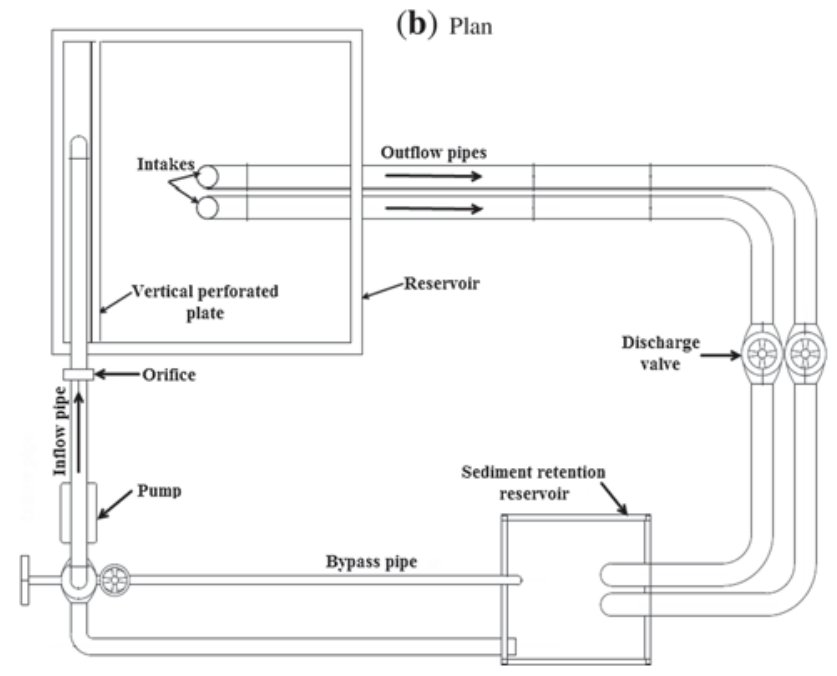

Figure 3. Schematic view of the experimental setup.

perforated vertical plate which make flow as uniform as possible was installed at upstream of the reservoir. The flow rate also was measured by an orifice. To simulate the sedimentation in the coastal situations, a bed with 0.1 slope was constructed and filled in with $1 \mathrm{~cm}$ sediment layer. It should be noted that the investigated beach in this paper can be considered as reflective beach. The mean diameter of used sediment was considered as similarity parameter to achieve the similarity between sediment mean size in the model and prototype. The Reynolds number for falling velocity of sediment particles $(R e=w d / v)$ in the water was less than approx 0.1, so Stokes law was used to determine the settling velocity of sediment particle. It can be described as

$$
w=\frac{d^{2}}{18 \mu}\left(\gamma_{s}-\gamma_{f}\right)
$$

where $w$ is the particle settling velocity, $\mu$ is the viscosity, $\gamma_{s}$ and $\gamma_{f}$ are specific weight of sediment and fluid respectively and $d$ is the particle diameter. By considering Eq. 1, the ratio of particle settling velocity in the model to particle settling velocity in the prototype is as follows:

$$
w_{r}=\frac{d_{r}^{2}}{\mu_{r}}\left(\gamma_{s}-\gamma_{f}\right)_{r}
$$

thus:

$$
w_{r}=\frac{d_{r}^{2}}{\left(S G_{s}-1\right)_{r}} \text { or } d_{r}^{2}=w_{r}\left(S G_{s}-1\right)_{r}
$$

where $S G_{s}$ is the specific gravity of sediment. On the other hand to establish the similarity of sediment transport, the distribution of sediment concentration in the model and prototype must be same, so the Rose equation for model and prototype must be similar. Rose equation indicates the vertical distribution of suspended particles in uniform flows [28]:

$$
\frac{C}{C_{a}}=\left[\frac{(h-y) a}{y(h-a)}\right]^{z}
$$

where $C$ is concentration at any level, $y, C_{a}$ is the concentration at some arbitrary level $y=a, h$ is mean flow depth and $Z$ is equal to $w / \beta k u^{*}$ which $\beta$ is proportionality coefficient between diffusivity for sediment and momentum which is assumed to be one [29], $k$ is Von Kármán constant, approximately 0.408 [30] and $u^{*}$ is shear velocity which is equal to $\sqrt{g R s}$. In order to establish similarity, the magnitude of $Z$ in Rose equation must be same for model and prototype.

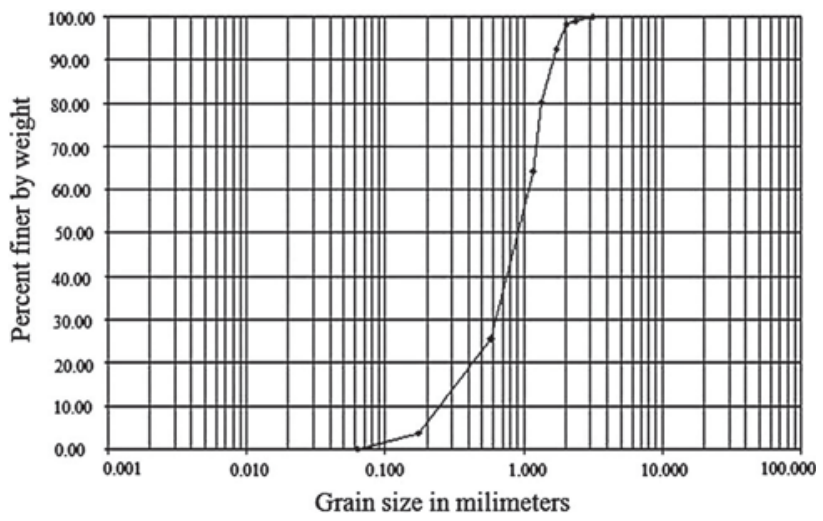

Figure 4. Diagram of grain size for model.

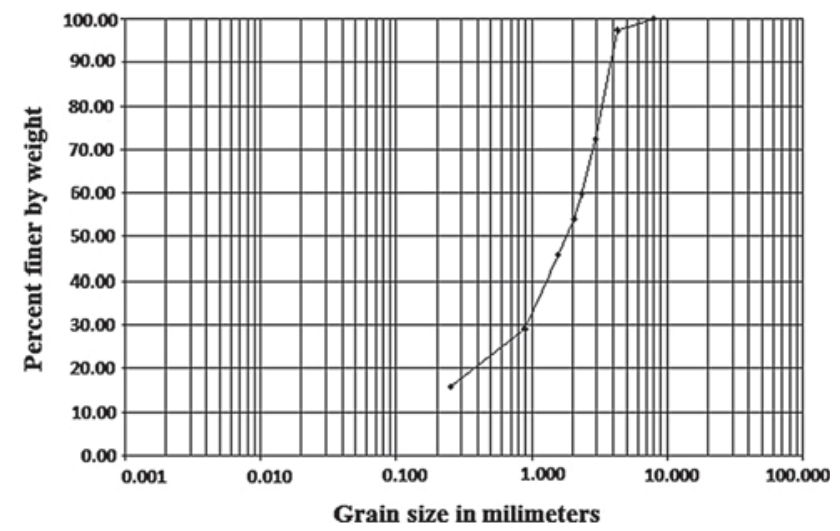

Figure 5. Diagram of grain size for prototype. 


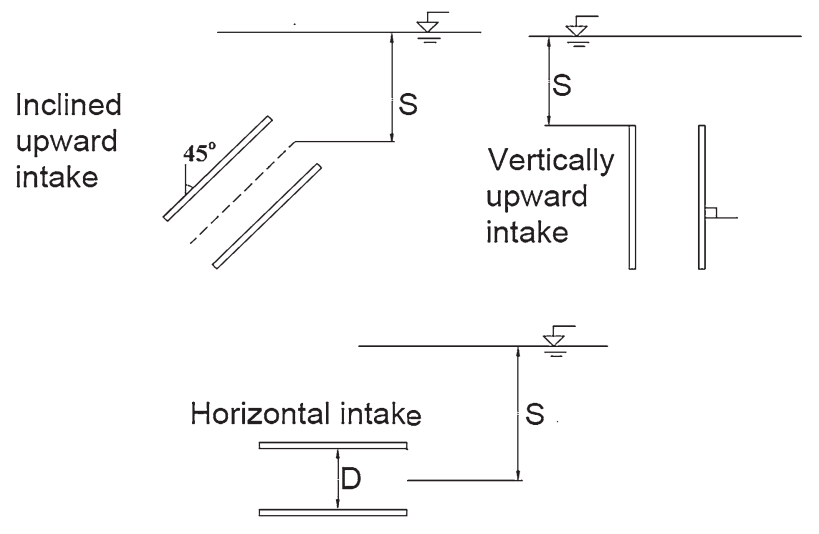

Figure 6. Different employed intake directions.

$$
z_{p}=z_{m}
$$

then

$$
\left(\frac{w}{\beta k u^{*}}\right)_{m}=\left(\frac{w}{\beta k u^{*}}\right)_{p} \rightarrow\left(\frac{w}{u^{*}}\right)_{m}=\left(\frac{w}{u^{*}}\right)_{p}
$$

thus:

$$
w_{r}=u_{r}^{*}=\sqrt{(g R s)_{r}}=\sqrt{R_{r}}=L_{r}^{1 / 2}
$$

where $r$ index means the ratio of each parameter in the model to the same parameter in the prototype. Eqs. (3) and (7), yields

$$
d_{r}=L_{r}^{1 / 4}\left(S_{s}-1\right)_{r}^{1 / 2} .
$$

Figures 4 and 5 indicate diagram of grain size for model and prototype, respectively.

In order to measure the tangential velocity of vortices $\left(V_{\theta}\right)$, particle tracking velocimetry (PTV) method was employed. The system of PTV was comprised of a digital camera, light system and a data analysis software run on a regular computer. The camera was regular CCD equipped CCTV camera and was operated at frame rate of $30 \mathrm{fps}$. Light source was provided by two high power halogen lights, which were placed on the upstream side of the model. Granola Polypropylene was utilized as particle tracer to visualize vortex flow. The relative density of these particles was about 0.99 so they remained floating over the water surface. The system followed the tracers continuously and the movement of the tracer could be followed on the computer screen. The software compared the 30 pictures, calculated velocity vectors for each tracer and saved it in a data-file, which contained the location, direction and magnitude for each of these vectors. Experiments were repeated for six different relative submerged depths $(S /$ $D$ ) and three different directions of the intakes (figure 6).

After each test, the sediment deposition was repeated and recovered for next test. With respect to density and the range of grain sizes, the rate of the sediment transport $\left(Q_{s}\right)$ was measured by using the 200 and $100 \mu \mathrm{m}$ sieve in front of inlet pipe of sediment retention reservoir.

\section{Results and discussions}

For each experiment, the discharge of intake $\left(Q_{i}\right)$, discharge of sediment $\left(Q_{S}\right)$ and strength of formed vortex $(\Gamma)$ were measured and class of vortices and Carriveau's category (PSS and NPSS) were defined in different hydraulic conditions. The strength of vortices can be computed from the proposed equation in free vortex zone $\left(\Gamma=2 \pi r V_{\theta}\right)$ by Rankine [31]. Where $\Gamma$ is strength of vortex, $r$ is distance of measured point from the center of vortex core.

At first, experiments were conducted on vertical intake position and the results for six different submerged depths are

Table 1. Experimental results for vertical dual intakes.

\begin{tabular}{llcccc}
\hline & & & & \multicolumn{2}{c}{ Class of vortices } \\
\cline { 5 - 6 }$F r$ & $S / D$ & $N_{\Gamma}$ & $F r_{s}$ & Right & Left \\
\hline 0.32 & 2.4 & 1.947 & 0.25 & C, PSS & A, NPSS \\
0.34 & 2.62 & 1.691 & 0.243 & C, PSS & A, NPSS \\
0.36 & 2.95 & 1.119 & 0.236 & C, PSS & A, NPSS \\
0.39 & 3.21 & 0.860 & 0.233 & C, PSS & A, NPSS \\
0.41 & 3.611 & 0.754 & 0.231 & C, PSS & B, NPSS \\
0.44 & 4.59 & 0.439 & 0.229 & C, PSS & C, PSS \\
\hline
\end{tabular}

Table 2. Experimental results for inclined dual intakes with angle of $45^{\circ}$.

\begin{tabular}{llcccc}
\hline & & & & \multicolumn{2}{c}{ Class of vortices } \\
\cline { 5 - 6 }$F r$ & $S / D$ & $N_{\Gamma}$ & $F r_{s}$ & Right & Left \\
\hline 0.32 & 2.4 & 1.413 & 0.23 & C, PSS & A, NPSS \\
0.34 & 2.62 & 1.177 & 0.228 & C, PSS & A, NPSS \\
0.36 & 2.95 & 0.986 & 0.226 & C, PSS & A, NPSS \\
0.39 & 3.21 & 0.737 & 0.225 & C, PSS & C, NPSS \\
0.41 & 3.611 & 0.615 & 0.221 & C, PSS & C, NPSS \\
0.44 & 4.59 & 0.504 & 0.218 & C, PSS & C, PSS \\
\hline
\end{tabular}

Table 3. Experimental results for horizontal dual intakes.

\begin{tabular}{llcccc}
\hline & & & & \multicolumn{2}{c}{ Class of vortices } \\
\cline { 5 - 6 }$F r$ & $S / D$ & $N_{\Gamma}$ & $F r_{s}$ & Right & Left \\
\hline 0.32 & 2.4 & 1.262 & 0.252 & C, PSS & A, NPSS \\
0.34 & 2.62 & 0.970 & 0.247 & C, PSS & A, NPSS \\
0.36 & 2.95 & 0.723 & 0.238 & C, PSS & A, NPSS \\
0.39 & 3.21 & 0.564 & 0.236 & C, PSS & C, NPSS \\
0.41 & 3.611 & 0.504 & 0.234 & C, PSS & C, NPSS \\
0.44 & 4.59 & 0.444 & 0.232 & C, PSS & C, PSS \\
\hline
\end{tabular}




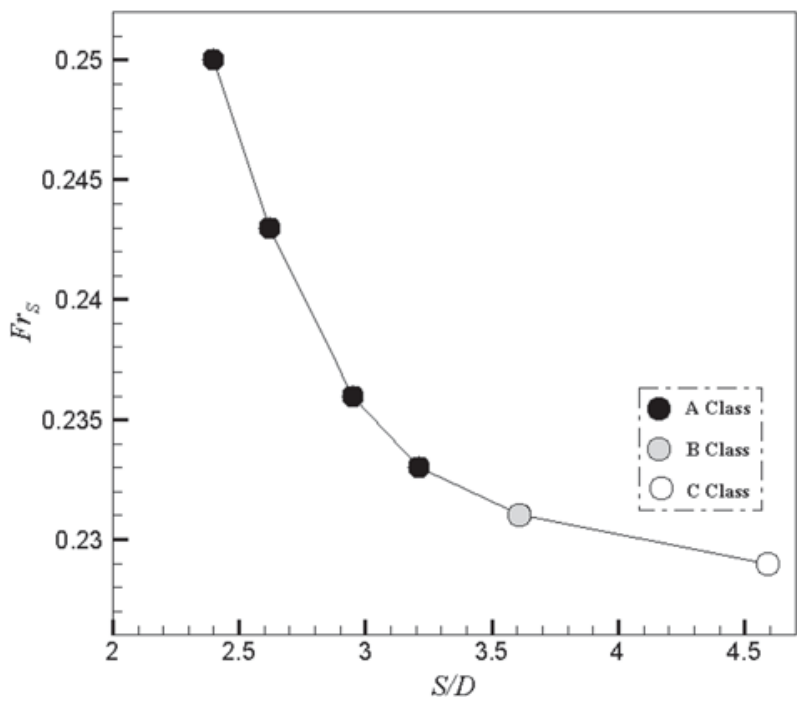

Figure 7. $F r_{s}$ versus $S / D$ for vertical dual intakes.

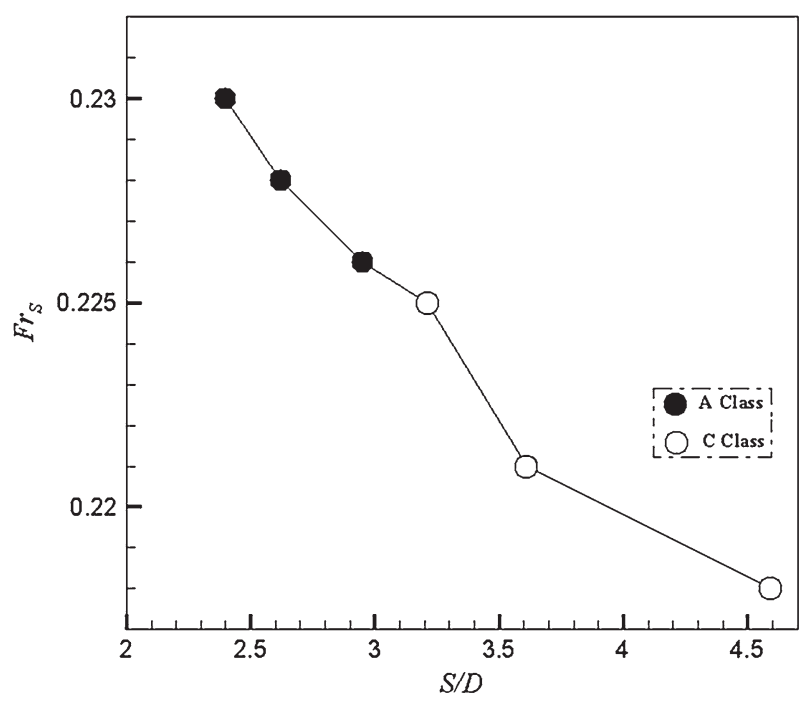

Figure 8. Effect of $S / D$ on $F r_{s}$ for inclined dual intakes with angle of $45^{\circ}$.

shown in table 1 . Then experiments were conducted on the horizontal and inclined (with angle of $45^{\circ}$ ) intakes, respectively as same as vertical intake (tables 2, 3). Where $F r$ is Froude number of intake $\left(\frac{Q_{i}}{A_{\mathrm{i}}(g D)^{0.5}}\right), S / D$ is non-dimensional submerged depth, $N_{\Gamma}$ is circulation number $\left(N_{\Gamma}=\Gamma / V_{i} D\right)$ and $F r_{S}$ is Froude number of sediment $\left(\frac{Q_{S}}{A_{\mathrm{i}}(g d)^{0.5}}\right)$.

Figure 7 indicates effect of $S / D$ on $F r_{s}$ for vertical dual intakes direction.

This figure infers that as $S / D$ increases, the sediment discharge decreases. It should be mentioned that increasing the submerged depth means decreasing the vortex strength [5]. As can be seen from figure 7, sediment discharge is

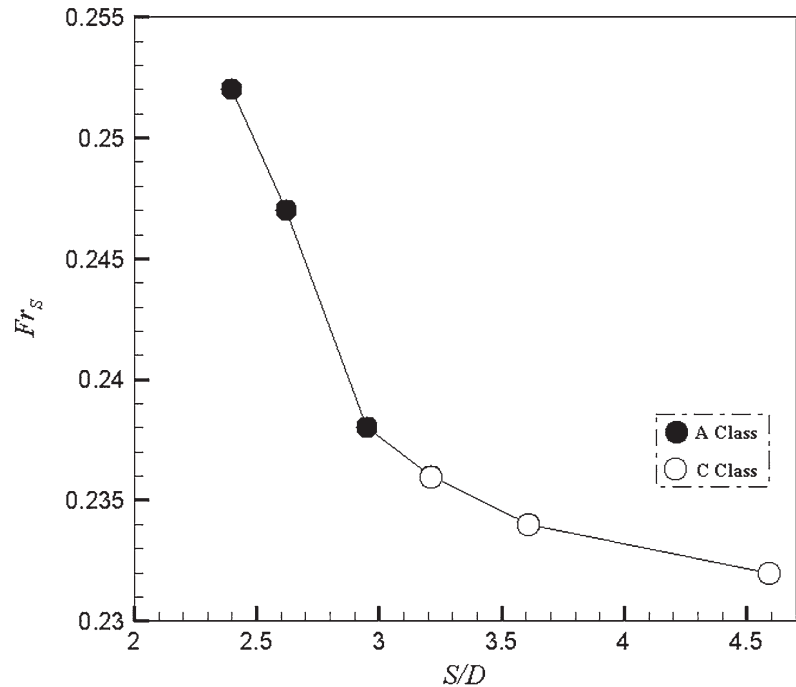

Figure 9. Effect of $S / D$ on $F r_{s}$ for horizontal dual intakes.

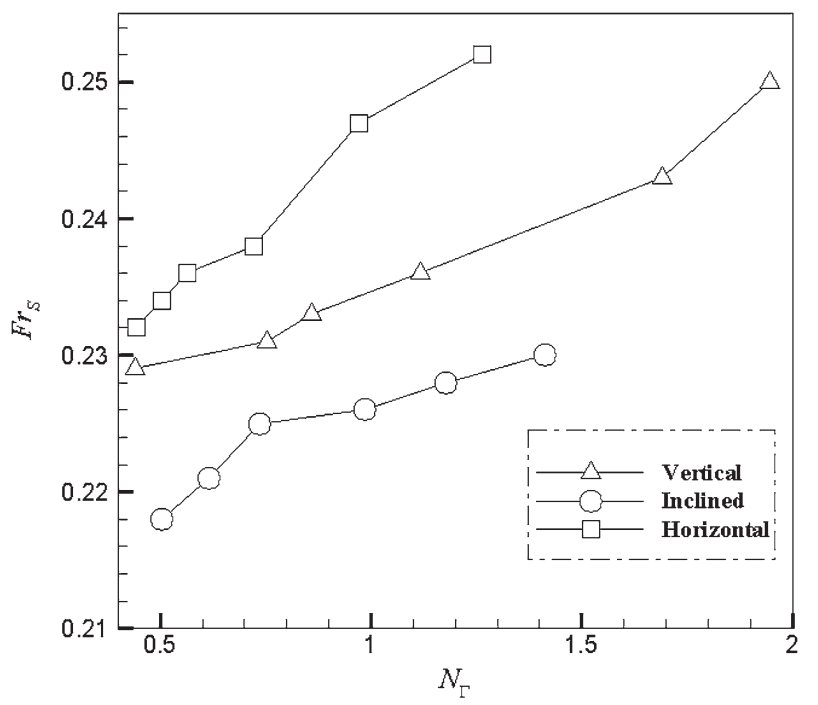

Figure 10. Comparison $F r_{s}$ versus circulation number for three different geometries of dual intakes.

considerably affected by the strength of vortex which occurred at the intakes. Figures 8 and 9 demonstrate the effect of $S / D$ on $F r_{s}$ for inclined (with angle of $45^{\circ}$ ) and horizontal dual intakes, respectively.

Figure 8 shows that $F r_{s}$ in inclined dual intakes is lower than vertical position under an identical condition, since the circulation decreases in this position. As can be seen from figures 7 and 8 , by changing the angle of pipe intakes from vertical to $45^{\circ}$, the $F r_{s}$ decreases $8 \%$ and $4.8 \%$ for minimum and maximum submerged depth, respectively (tables 1,2). Furthermore, it can be observed from figures 8 and 9 that by changing the angle of pipe intakes from $45^{\circ}$ to horizontal, the $F_{s}$ increases $8.7 \%$ and $6.4 \%$ for minimum and maximum submerged depth, respectively (tables 2, 3). In figure 10, the results of the sediment transport for 
vertical, horizontal and inclined (angle of $45^{\circ}$ ) dual intakes were compared regarding the circulation number $\left(N_{\Gamma}=\Gamma /\right.$ $\left.V_{i} D\right)$ and $F r_{s}$.

This figure indicates that the lowest sediment discharge was occurred for the inclined dual intakes with angle of $45^{\circ}$. Moreover, figure 10 demonstrates that although the strength of vortices was reduced from vertical to horizontal position (tables 1, 3); however, in such as this condition, the subsurface vortices will form from the bed of the reservoir. Therefore, the potential of sediment transport will increase in this case as can be seen in figure 10. It could be concluded that formation of sub-surface vortices from the bed has more effect on sediment transport in comparison with increasing the vortex strength. Thus, the inclined dual intakes are more suitable than the vertical and horizontal dual intakes.

\section{Conclusions}

In the present experimental study, the effect of vortex formation on sediment transport at dual pipe intakes by changing intake discharge and angle of dual pipe intakes were investigated. By considering the results, the following conclusions may be drawn from this study:

- By varying the pipe intakes angle from $45^{\circ}$ to horizontal, the $F r_{s}$ increased $8.7 \%$ for minimum submerged depth and increased $6.4 \%$ for maximum submerged depth.

- By varying the pipe intakes angle from $45^{\circ}$ to vertical, the sediment discharge increased $8 \%$ for minimum submerged depth and increased $4.8 \%$ for maximum submerged depth.

- The weakest vortex strength was occurred in the horizontal dual pipe intakes but in the inclined dual pipe intakes the amount of sediment transport was less than the horizontal dual pipe intakes and consequently the inclined dual pipe intakes are more suitable than two other types of dual pipe intakes.

\section{List of symbols}

$D \quad$ diameter of pipe intake (m)

$D$ particle diameter (m)

$\mathrm{Fr} \quad$ Froude number

$\mathrm{Fr}_{s} \quad$ sediment Froude number

$G \quad$ gravity $\left(\mathrm{m} / \mathrm{s}^{2}\right)$

$K \quad$ Von Kármán constant

$N_{\Gamma} \quad$ circulation number

$Q_{i} \quad$ intake discharge (lit/s)

$Q_{s} \quad$ rate of sediment transport $\left(\mathrm{cm}^{3} / \mathrm{s}\right)$

Re Reynolds number

$S \quad$ submerged depth (m)

$S_{c} \quad$ critical submerged depth (m)

$S G \quad$ specific gravity
$S / D \quad$ non-dimensional submerged depth

$u^{*} \quad$ shear velocity $(\mathrm{m} / \mathrm{s})$

$V_{\theta} \quad$ tangential velocity $(\mathrm{m} / \mathrm{s})$

$w \quad$ particle falling velocity $(\mathrm{m} / \mathrm{s})$

We Weber number

$\beta \quad$ ratio of particle distribution coefficient to momentum coefficient

$\Gamma \quad$ vortex strength $\left(\mathrm{m}^{2} / \mathrm{s}\right)$

$\gamma_{s} \quad$ specific weight of sediment $\left(\mathrm{N} / \mathrm{m}^{3}\right)$

$\gamma_{f} \quad$ specific weight of fluid $\left(\mathrm{N} / \mathrm{m}^{3}\right)$

$\mu \quad$ viscosity $(\mathrm{kg} / \mathrm{m} . \mathrm{s})$

$\rho \quad$ density of fluid $\left(\mathrm{kg} / \mathrm{m}^{3}\right)$

$v \quad$ kinematic viscosity $(\mathrm{kg} / \mathrm{s} . \mathrm{m})$

\section{References}

[1] Zheng Y and Alsaffar A 2000 Water intake sediment problems in thermal power plants. ASCE 68(4): 1-8

[2] Knauss J 1987 Swirling flow problems at intakes. Rotterdam: A.A. Balkema

[3] Amiri S M, Zarrati A R, Roshan R and Sarkardeh H 2011 Surface vortex prevention at power intakes by horizontal plates. J. Water. Manag. (ICE) 164(4): 193-200

[4] Kundu P 1990 Fluid mechanics. London: Academic Press.

[5] Sarkardeh H, Zarrati A R and Roshan R 2010 Effect of intake head wall and trash rack on vortices. J. Hydraul. Res. 48(1): 108-112

[6] Carriveau R, Kopp G A and Baddour R 2009 Free-surface stretching-sustained intake vortices. J. Hydraul. Res. 47(4): 486-491

[7] Liu Z 2001 Sediment transport. Aalborg: Aalborg University.

[8] Anwar H O and Amphlett M B 1980 Vortices at vertically inverted intakes. J. Hydraul. Res. 18(2): 123-136

[9] Anwar H O, Weller J A and Amphlett M B 1978 Similarity of free vortex at horizontal intake. J. Hydraul. Res. 16(2): 95-105.

[10] Berge J -P 1966 A study of vortex formation and other abnormal flow in a tank with and without a free surface. $L a$ Houille Blanche 1: 13-40

[11] Chang E 1977 Review of literature on drain vortices in cylindrical tanks. Secondary Review of literature on drain vortices in cylindrical tanks. U.K, BHRA Report

[12] Daggett L L and Keulegan G H 1974 Similitude in free-surface vortex formation. ASCE J. Hydraul. Div. 100(1): 1565-1580

[13] Hite J E and Mih W 1994 Velocity of air-core vortices at hydraulic intakes. J. Hydraul. Eng. 120(3): 284-297

[14] Jain A K, Ranga Raju K G and Garde R J 1987 Vortex formation at vertical pipe intakes. J. Hydraul. Div. ASCE 104(10): 1429-1448

[15] Odgaard J A 1986 Free-surface air core vortex. J. Hydraul. Eng. 112(7): 610-620

[16] Reddy Y R and Pickford J A 1972 Vortices at intakes in conventional sumps. Waterpower 108-109

[17] Sarkardeh H, Zarrati A R, Jabbari E and Roshan R 2012 Discussion of prediction of intake vortex risk by nearest neighbors modeling. J. Energy Eng. ASCE 137(6): 701-705 
[18] Denny D F and Young G H J 1957 The prevention of vortices and swirl at intakes. Secondary The Prevention of Vortices and Swirl at Intakes. Lissabon. Paper C1

[19] Jansen R B 1988 Advanced dam engineering for design, construction, and rehabilitation. Van Nostrand Reinhold.

[20] Yildirim N, Taştan K and Arsalan M M 2009 Critical submerged depth for dual pipe intakes. J. Hydraul. Res. 47(2): 242-249

[21] Yildirim N, Eyüpoğlu A S and Taştan K 2012 Critical submerged depth for dual rectangular intakes. J. Energy Eng. 138(4): 237-245

[22] Kerssens P M and Van Urk A 1986 Experimental studies on sedimentation due to water withdrawal. J. Hydraul. Eng. 112(7): 641-656

[23] Johnson P L 1988 Hydro-power intake design considerations. J. Hydraul. Eng. 114(6): 651-661

[24] Michell F, Ettema R and Muste M 2006 Sediment control at water intake for large thermal-power station on a small river. J. Hydraul. Eng. 132(5): 440-449
[25] Moghadam M K, Bajestan M S and Sedghi H 2010 Sediment entry investigation at the 30 degree water intake installed at a trapezoidal channel. World Appl. Sci. J. 11(1): 82-88

[26] Raudkivi A J 1993 Sedimentation: Exclusion and removal of sediment from diverted water. New York: Taylor \& Francis.

[27] Padmanabhan M and Hecker G E 1984 Scale effects in pump sump models. J. Hydraul. Eng. 110(11): 1540-1556

[28] Orton P M and Kineke G C 2011 Comparing calculated and observed vertical suspended-sediment distributions from a hudson river estuary turbidity maximum. Estuar. Coastal Shelf Sci. 52(3): 401-410

[29] McAnally W H and Mehta A J 2009 Coastal zone and estuaries. Encyclopedia of life support systems. F. I. Islaay: Eolss Publishers

[30] Nowell A R M 1983 The benthic boundary layer and sediment transport. Rev. Geophys. Space Phys. 21: 1181

[31] Rankine W J M 1858 Manual of applied mechanics. London: C. Griffen Co. 